Case Report

\title{
Anesthetic management of penetrating nail injury brain: a case report
}

\begin{abstract}
Penetrating injury brain is common after accidental falls, sharp projectile injury, suicidal attempts etc. We present an unusual case of accidental penetrating nail injury brain in a 19 year old male patient presenting for emergency craniotomy. This case report highlights the difficulties faced in the anesthetic management of patients presenting with penetrating injury brain.
\end{abstract}

Keywords: cerebral perfusion pressure, emergency craniotomy, nail injury, penetrating brain injury

\author{
Volume 5 Issue I - 2016

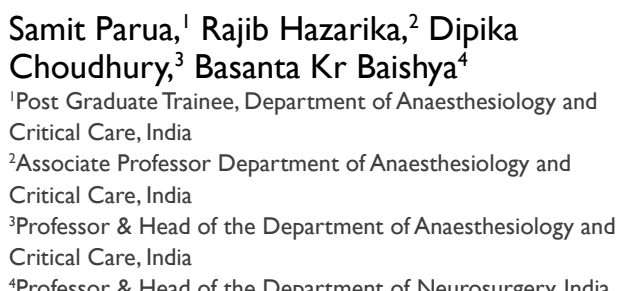

Correspondence: Samit Parua, Post Graduate Trainee, Department of Anaesthesiology and Critical Care, Room No 1 I 2, PG Hostel No 5, Gauhati Medical College and Hospital, Bhangagarh Guwahati Assam, 78I032, India, Tel 08399039145, Emailsamitparua@gmail.com

Received: May 22, 2016 | Published: June 28, 2016
Abbreviations: ASA, American society anesthesiologist; $\mathrm{CBF}$, cerebral blood flow; MAC, minimum alveolar concentration; RSI, rapid sequence induction; MAR, mean arterial pressure; ICU, intensive care unit; $\mathrm{CPP}$, cerebral perfusion pressure; $\mathrm{CMRO}_{2}$, cerebral metabolic oxygen requirement

\section{Introduction}

Penetrating injury brain commonly occurs as a result of accidental fall into shrapnel, suicidal attempts, low velocity projectile injury during construction work, high velocity projectile during bomb blasts etc. ${ }^{1-3}$ Usually low velocity injuries have a good prognosis. Surgical extraction of such projectiles can be successfully done, when they are partly impacted to the skull bone but their blind removal carries the risk of secondary brain injury. ${ }^{4}$ This case report illustrates the anesthetic challenges encountered in the surgical management of a patient presenting with a penetrating nail injury brain at a tertiary care hospital.

\section{Case report}

A 19 year old male patient presented in the emergency department of Gauhati Medical College and Hospital with a 2 day history of traumatic nail injury brain. Patient was referred to this institute for urgent neurosurgical intervension. The patient had a post traumatic loss of consciousness, now complaining of severe headache with frequent nausea vomiting and weakness of the right upper limb. Household repairs were going on in his when he accidentally slipped and fell head on a nail. He was immediately rushed to the nearby health facility, from where he was referred to Gauhati Medical College. Patient was examined by the emergency neurosurgery and neuroanaesthesia team.

He had a Glasgow Coma Score of 13/15, no other external injuries were noted. A nail head entry wound was visible on his scalp with bloody discharge around it (Figure 1). His right upper limb power was 3/5 as per Medical Research Council grading with poor hand grip in comparison to the opposite side with no other focal neurological deficit. Routine blood investigations, coagulation profile were normal. Skull X-ray showed a vertically oriented radio-opaque nail penetrating through the frontal bone of skull and into the brain parenchyma (Figure 2). Computerized tomography scan revealed a $7 \mathrm{~cm}$ long nail penetrated through the frontal bone and into the left frontal lobe of brain (Figure 3). It was evident that nail required immediate surgical removal. An informed consent was obtained from the patient for the operative procedure \& general anaesthesia. Patient had received Tetanus Immunoglobulin $250 \mathrm{IU}$ and Inj Tetanus Toxoid I.M in the emergency department.

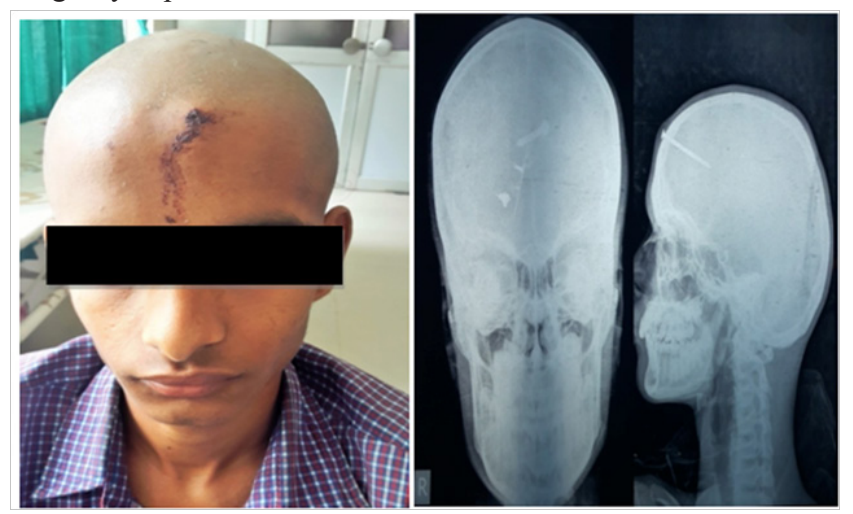

Figure I \& 2 Showing entry wound over the scalp and in x ray.

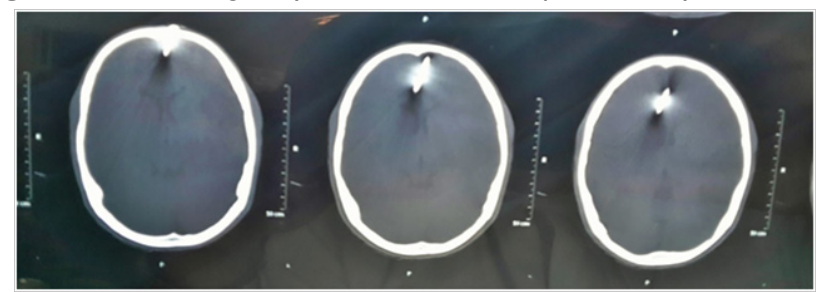

Figure 3 CT SCAN (bony window) showing intra brain parenchymal extension of the nail. 
After being shifted to the neurosurgical operating room Standard American Society of Anaesthesiologists (ASA) monitors were attached and baseline vitals were recorded. 18G IV cannulation was done in each forearm and warm normal saline was started slowly. Patient received broad spectrum antibiotics as per hospital protocol. Inj Levepiracetam $1000 \mathrm{mg}$ IV and Inj Fentanyl citrate 60 micro grams IV were also administered. Patient was preoxygenated for 3 minutes with $100 \%$ oxygen. Rapid sequence induction (RSI) was done with $80 \mathrm{mg}$ Propofol and muscle relaxation was achieved with $40 \mathrm{mg}$ of Inj Rocuronium Bromide. Airway was secured with a 8 millimeter internal diameter reinforced endotracheal tube which was fixed at $22 \mathrm{cms}$ after bilateral air entry was checked to be equal and adequate. Anaesthesia was maintained with oxygen:air in 1:2 ratio (flow $2 \mathrm{~L} /$ minute) with 0.4 to $0.8 \%$ Isoflurane. Patient was ventilated with a tidal volume of $6-8 \mathrm{ml} / \mathrm{kg}$, with a respiratory rate of 12 to 14 breaths perminute. Divided doses of Inj Rocuronium Bromide were used intraoperatively. After antiseptic dressing \& draping, local infiltration of the surgical site with $20 \mathrm{ml}$ of $1 \%$ lignocaine was done. A $9 \mathrm{~cm}$ curved incision was made across the nail head to raise a scalp flap (Figure 4). A small $4 \mathrm{~cm}$ diameter craniotomy trephine was created adjoining the nail to widen the interphase between it and the skull. Bone adjoining the nail was gradually nibbled off, the nail became loose, the circular piece of bone was removed and under direct vision using a plain forceps, the nail head was stabilised and gradually pulled out of the brain parenchyma (Figure $5 \& 6$ ). The surgical field was dry and the only bleeding was noted from the scalp wound. The nail measured 7 centimeters (Figure 7). The surgical site was irrigated copiously \& gently with warm normal saline from a $10 \mathrm{ml}$ syringe. The opening in the skull was covered by the trephined piece of bone $\&$ the wound was closed in layers. Patients received Inj Paracetamol $1000 \mathrm{mg}$ slows IV intraoperatively. Intraoperatively patients was normocapnic and no episodes of hypoxaemia $(\mathrm{Sa} 02<92 \%)$ developed. Throughout the procedure we maintained a mean arterial pressure; of greater than $70 \mathrm{~mm} \mathrm{Hg}$. At the end of the procedure patient was reversed adequately and later shifted to neuro surgical intensive care unit. The operative procedure was completed within 60 minute. Patient received $1200 \mathrm{ml}$ of isotonic saline intraoperatively; with an estimated blood loss of $200 \mathrm{ml}$. Intraoperative urine output was 80 $\mathrm{ml}$. The patient recovered uneventfully over the next 10 days and he was subsequently discharged on the fourteenth postoperative day. $\mathrm{He}$ regularly followed up at the neurosurgical outpatient department.

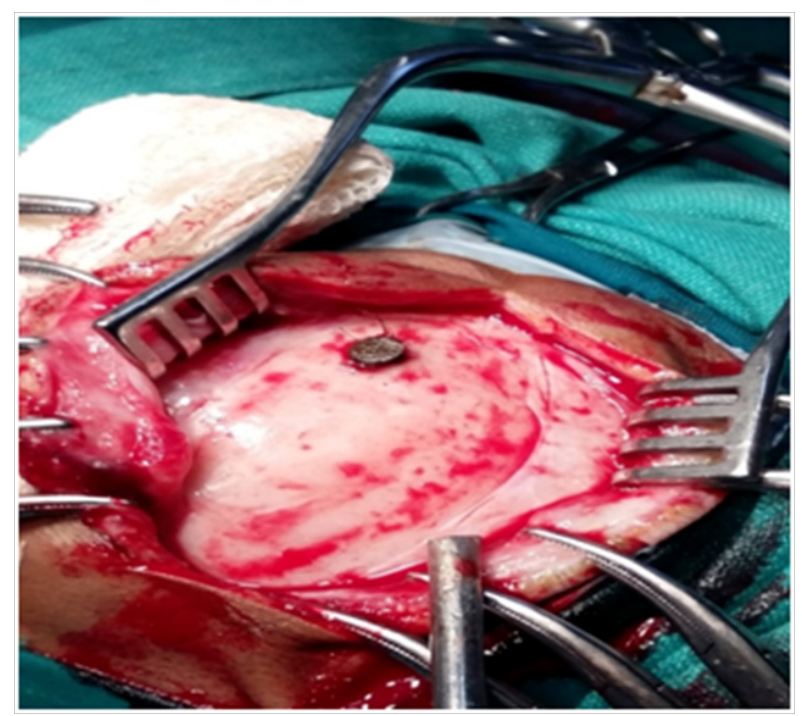

Figure 4 Nail lodged head visible through the skull bone.

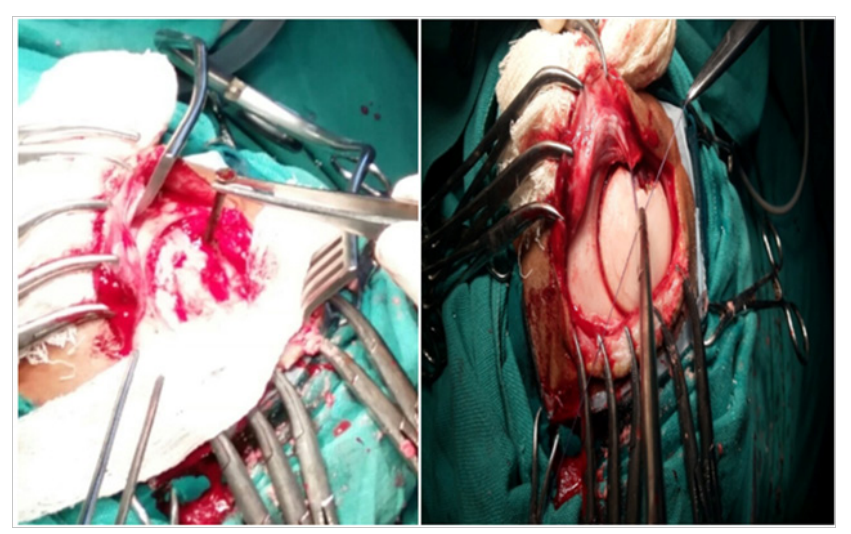

Figure 5 \& 6 Intraparenchymal nail extraction and craniotomy closure.

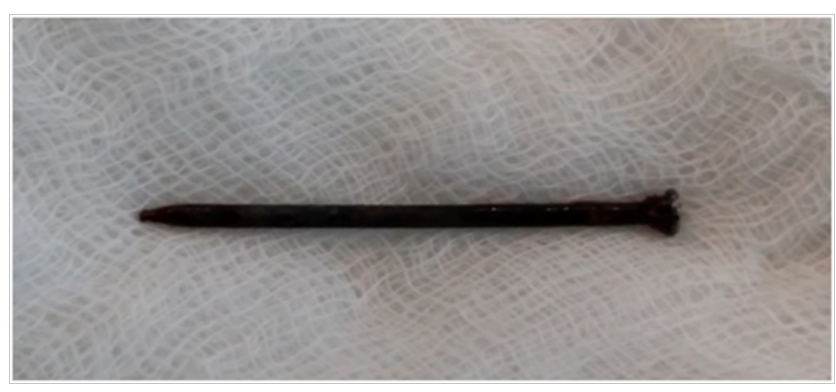

Figure 7 The lodged nail.

\section{Discussion}

Penetrating nail injury brain is a emergency situation which requires prompt medical management \& neurosurgical intervension. Following penetrating injury to the brain, pre-hospital care involves patient stabilization \& securing the penetrated object to prevent further brain injury. If the patient comes in a life threatening situation, adequate resuscitation with thorough assessment of any form of neurological deficit is important before any surgical intervension to remove the penetrating object is attempted. ${ }^{5}$ In addition to nails, penetrating injury brain has also been reported with other objects like screw driver, scissors, knives, crowbar, spears etc.,5 Usually penetrating objects do not intracranial bleed at the time of impalement but due to high velocity of impact have a tamponade effect. But they may bleed once that tamponade effect ceases to act i.e. during their extraction. ${ }^{6}$ The visible nail head in our patient guided the surgeons in the successful extraction. Some authors report using this tamponade effect of projectile injury by delaying extraction, hence allowing a stable clot formation around the object. ${ }^{7}$

Our patient presented 2 days after the injury \& we planned urgent removal as he was having focal neurodeficit and signs of raised intracranial pressure. Our other immediate concerns were infection \& seizures. Majority of the penetrating nail injury brain cause minor neurological deficit. ${ }^{3,8}$ The injuries are limited locally along the nail track. ${ }^{9}$ Our patient complained of mild weakness in the right upper limb post trauma. Hypoxia and hypotension correction prevent secondary brain injury \& are the chief priorities during the perioperative management of patients with penetrating brain injury. A single episode of associated hypotension increases morbidity and doubles mortality. ${ }^{10}$

Surgical blood loss and anesthetic drugs further predispose these patients to hypotension. Both invasive and non invasive monitoring 
are important and should include electrocardiogram, pulse oxymetry, capnography, temperature, urine output, invasive arterial pressure monitoring, arterial blood gas analysis and perioperative blood glucose monitoring are important. Central venous access may be useful for administration of vasoactive drugs and central venous pressure monitoring during resusciation. Intracranial pressure (ICP) monitoring has gold standard recommendation in patients presenting with traumatic brain injury. Anesthetic goals in these patients include maintainance of adequate cerebral perfusion pressure $\&$ intracranial pressures, proper plane of anaesthesia \& perioperative analgesia, observing normocapnia \& hypoxia prevention during mechanical ventilation, euglycaemic state with hypothermia and hyperthermia prevention.

Analgesia is most essential, as any noxious stimuli may cause sympathetic surge increasing cerebral blood flow (CBF), cerebral metabolic oxygen requirement $\left(\mathrm{CMRO}_{2}\right)$, and ICP. All volatile agents upto 1 minimum alveolar concentration (MAC), usually reduce $\mathrm{CMRO}_{2}$, cause cerebral vasodilation, increase cerebral blood flow (CBF) further increasing ICP. Inhalational anesthetics reduce cerebral responsiveness to carbon dioxide. Sevoflurane below $1 \mathrm{MAC}$ is best suited for neurosurgical interventions. Use of inhalational nitrous oxide is obsolete in neurosurgical cases. Intravenous induction agents on the other hand reduce $\mathrm{CMRO}_{2}, \mathrm{CBF}$, and ICP.

Propofol induction in these patients causes significant hypotension which may further reduce cerebral perfusion pressure (CPP). Neuromuscular blocking drugs allow controlled ventilation \& prevent coughing or straining reflexes in the operated patient. Rocuronium has minimal cardiovascular effects with no histamine releasing property $\&$ is the muscle relaxant of choice in neuroanaesthesia. Patient positioning with extremes of flexion or rotation of the head impedes venous drainage from brain, further raising the ICP. Controlled ventilation aims at maintaining normocapnia, while preventing hypoxia. Hyperventilation to maintain a $\mathrm{PaCO}_{2}$ value of $30-35 \mathrm{~mm}$ $\mathrm{Hg}$ is useful in patients with intracranial hypertension (ICP $\geq 20 \mathrm{~mm}$ $\mathrm{Hg}$ ) with jugular venous oxygen saturation estimation as a measure of adequacy of cerebral oxygenation. A reduction in $\mathrm{PaCO}_{2}$ reduces cerebral blood volume and ICP due to cerebral vasoconstriction. But hyperventilation may cause cerebral hypoperfusion, further causing ischaemia. ${ }^{11}$ Adequate perioperative hydration along with the use of vasopressors to maintain a $\mathrm{CPP}$ of $60 \mathrm{~mm} \mathrm{Hg}$ maintains $\mathrm{CBF}$ and tissue oxygenation. Maintainance of perioperative euglycaemic state is essential. 20\% Mannitol may be used perioperatively for control of acute increase in ICP, but may cause intravascular volume depletion, hypotension, renal complications, and hyperkalaemia and rebound intracranial hypertension. ${ }^{12}$

Induced hypothermia (32-35.8) $\mathrm{C}$ is known to have neuroprotective action demonstrated in animal studies. Moderate hypothermia effectively reduces ICP and reduces $\mathrm{CMRO}_{2}$ and is useful in the management of raised ICP refractory to medical therapy. ${ }^{11}$ I.V. Barbiturates although lower ICP but cause significant cardiovascular instability \& are indicated in cases of refractory intracranial hypertension. Postoperative intensive care unit (ICU) based care is necessary for these patients. Our patient received prophylactic anticonvulsants and antibiotics prior to induction. We used Propofol for induction in our patient as we went for RSI. Our patient was kept normocapnic, normothermic, nonhypoxic intraoperatively maintaining a MAP of $>70 \mathrm{~mm} \mathrm{Hg}$, with adequate planes of anaesthesia and analgesia. His perioperative course was uneventful \& recieved intensive care unit (ICU) based care postoperatively.

\section{Conclusion}

Careful planning \& preparation with maintainance of anaesthetic goals is necessary in the anaesthetic management of patients with penetrating brain injury. Perioperative management continues to focus on prevention of secondary brain injuries and maintenance of CPP. Although advanced medical treatment has significant reduced mortality, still no single treatment modality alone has been shown to improve outcome in these group of patients.

\section{Acknowledgements}

None.

\section{Conflicts of interest}

The authors declare no conflict of interest.

\section{Funding}

None.

\section{References}

1. Dollahite $\mathrm{H}$, Collinge $\mathrm{C}$. Removal of a nail from bone after nail gun injury:a case report and utility of a classic technique. J Orthop Trauma. 2012;26(8):129-131.

2. Wei L, Hay L, Shuyu H, et al. Penetrating brain injury caused by nail guns:two case reports and a review of the literature. Brain Inj. 2012;26(13-14):1756-1762.

3. Schwarzschild M. Nail in the brain. N Engl J Med. 1993;328:620.

4. Justin MS, Jonathan JL, Salem IA. Management of non-missile penetrating brain injuries:a description of three cases and review of the literature. Skull Base Rep. 2011;1(1):39-46.

5. Jacobs LM, Berrizbeitia L D, Ordia J. Crowbar impalement of the brain. J Trauma. 1985;25(4):359-361.

6. Agu CT, Orjiaku ME. Management of a nail impalement injury to the brain in a non-neurosurgical centre:A case report and review of the literature. Int J Surg Case Rep. 2016;19:115-118.

7. Williams JR, Aghion DM, Doberstein CE, et al. Penetrating brain injury after suicide attempt with speargun: case study and review of literature. Front Neurol. 2014; 5:113

8. Jacob JT, Cohen-Gadol AA, Maher CO, et al. Trans-orbital penetrating brainstem injury in a child:a case report. J Neurosurg. 2005;102(3):350352.

9. Hussain M, Muhammad EB. Suicide bomb attack causing penetrating craniocerebral injury. Chin J Traumatol. 2013;16(1):51-53.

10. Chestnut RM, Marshall LF, Klauber MR. the role of secondary brain injury in determining outcome from severe head injury. J Trauma. 1993;34(2):216-222.

11. Cooles JP, Fryer TD, Coleman MR, et al. Hyperventilation following head injury effect on ischaemic burden and cerebral oxidative metabolism. Crit Care Med. 2007;35(2):568-578.

12. Helmy A, Vizcaychipi M, Gupta A. Traumatic brain injury intensive care management. Br J Anaesth. 2007;99(1):32-42. 